\title{
Liver Cancer pTX TNM Finding v6
}

National Cancer Institute

\section{Source}

National Cancer Institute. Liver Cancer PTX TNM Finding v6. NCI Thesaurus. Code C61169.

Liver cancer in which the primary tumor cannot be assessed. (from AJCC 6th Ed.) 